\title{
An optimized probucol microencapsulated formulation integrating a secondary bile acid (deoxycholic acid) as a permeation enhancer
}

This article was published in the following Dove Press journal:

Drug Design, Development and Therapy

29 September 2014

Number of times this article has been viewed

\author{
Armin Mooranian' \\ Rebecca Negrulj' \\ Nigel Chen-Tan ${ }^{2}$ \\ Gerald F Watts ${ }^{3}$ \\ Frank Arfuso ${ }^{4}$ \\ Hani Al-Salami' \\ 'Biotechnology and Drug \\ Development Research Laboratory, \\ School of Pharmacy, Curtin Health \\ Innovation Research Institute, \\ Biosciences Research Precinct, Curtin \\ University, ${ }^{2}$ Faculty of Science and \\ Engineering, Curtin University, ${ }^{3}$ School \\ of Medicine and Pharmacology, Royal \\ Perth Hospital, University of Western \\ Australia, ${ }^{4}$ School of Biomedical \\ Science, Curtin Health Innovation \\ Research Institute, Biosciences \\ Research Precinct, Curtin University, \\ Perth, Australia
}

\begin{abstract}
The authors have previously designed, developed, and characterized a novel microencapsulated formulation as a platform for the targeted delivery of therapeutics in an animal model of type 2 diabetes, using the drug probucol (PB). The aim of this study was to optimize PB microcapsules by incorporating the bile acid deoxycholic acid (DCA), which has good permeation-enhancing properties, and to examine its effect on microcapsules' morphology, rheology, structural and surface characteristics, and excipients' chemical and thermal compatibilities. Microencapsulation was carried out using a BÜCHI-based microencapsulating system established in the authors' laboratory. Using the polymer sodium alginate (SA), two microencapsulated formulations were prepared: PB-SA (control) and PB-DCA-SA (test) at a constant ratio (1:30 and 1:3:30, respectively). Complete characterization of the microcapsules was carried out. The incorporation of DCA resulted in better structural and surface characteristics, uniform morphology, and stable chemical and thermal profiles, while size and rheological parameters remained similar to control. In addition, PB-DCA-SA microcapsules showed good excipients' compatibilities, which were supported by data from differential scanning calorimetry, Fourier transform infrared spectroscopy, scanning electron microscopy, and energy dispersive $\mathrm{X}$-ray studies, suggesting microcapsule stability. Hence, PB-DCA-SA microcapsules have good rheological and compatibility characteristics and may be suitable for the oral delivery of PB in type 2 diabetes.
\end{abstract}

Keywords: artificial cell microencapsulation, diabetes, bile acids, probucol, antioxidant, antiinflammatory, BÜCHI B390

\section{Introduction}

Diabetes mellitus is a metabolic disorder classified as type 1 diabetes or type 2 diabetes (T2D). ${ }^{1,2}$ Type 1 diabetes is an autoimmune disease marked by the destruction of $\beta$-cells of the pancreas, resulting in a partial or complete lack of insulin production and the inability of the body to control glucose levels. ${ }^{3}$ T2D develops due to genetic and environmental factors that lead to tissue desensitization to insulin. ${ }^{4}$ Current therapies are aimed at resolving the persistent hyperglycemia by increasing available insulin or improving tissue sensitivity. ${ }^{5,6}$ However, damage of pancreatic $\beta$-cells and the build-up of free radicals and toxins, together with persistent inflammation, remain detrimental in diabetes treatment and long-term prognosis. ${ }^{7}$

There is growing evidence for the use of antioxidants as adjuncts in the treatment of T2D. ${ }^{8-10}$ Probucol (PB) is a drug that was initially developed to treat hyperlipidemia, but its strong anti-inflammatory and antioxidant properties have made it a potential therapeutic agent in the treatment of T2D. ${ }^{11,12}$ In addition, PB has shown a protective effect on pancreatic $\beta$-cells. ${ }^{13,14}$ It is highly lipophilic and accumulates extensively
Correspondence: Hani Al-Salami School of Pharmacy, Curtin University, GPO Box U1987, Perth, WA 6845, Australia

Tel +6I 892669816

Fax +6I 892662769

Email hani.al-salami@curtin.edu.au 
in adipose tissues. ${ }^{15}$ PB has very low bioavailability but its pharmacokinetic and pharmacodynamic parameters show great variation between individuals. ${ }^{16,17}$ Thus, the low and variable oral bioavailability and the non-linear distribution and clearance of PB contribute to the variability in its efficacy as well as its side effects. ${ }^{9,18}$ So, despite the huge potential of $\mathrm{PB}$ in T2D, its variable and poor kinetics remain major obstacles to its clinical use. ${ }^{9}$ Designing a novel and stable formulation with good rheological parameters and permeation-enhancing properties is anticipated to overcome these obstacles. This can be achieved by incorporating a bile acid with permeation-enhancing characteristics, such as deoxycholic acid (DCA), ${ }^{19}$ in a novel delivery system using artificial cell microencapsulation technology.

Artificial cell microencapsulation is commonly used to improve the delivery of lipophilic drugs that exhibit low bioavailability and poor dissolution and absorption kinetics. ${ }^{20}$ It encapsulates a drug using a biodegradable polymer such as sodium alginate (SA), which protects the drug and provides a $\mathrm{pH}$-sensitive targeted delivery after oral administration. The choice of polymer has a significant impact on the formulation properties and efficacy as well as on the drug's chemical and thermal characteristics. ${ }^{21}$ Previous work by the authors' research group ${ }^{19,20,22-27}$ on the formulation of the antidiabetic drug gliclazide, alone or combined with bile acids (in vitro and in vivo), and their recently designed and formulated microcapsule platform have demonstrated improved targeted delivery when using an SA-based formulation. Thus, this study aimed to examine the potential of these newly developed microcapsules in producing a novel and stable PB formulation suitable for oral delivery in T2D through the incorporation of the bile acid DCA.

\section{Materials and methods Materials}

PB (98\%), low-viscosity SA (99\%), and DCA (98\%) were purchased from Sigma-Aldrich Co., (St Louis, MO, USA). Calcium chloride dihydrate $\left(\mathrm{CaCl}_{2} \cdot 2 \mathrm{H}_{2} \mathrm{O}, 98 \%\right)$ was obtained from Scharlab S.L (Sentmenat, Spain). All solvents and reagents were supplied by Merck KGaA (Darmstadt, Germany) and were of high-performance liquid chromatography grade and used without further purification.

\section{Drug preparation}

Stock suspensions of PB (20 mg/mL) and DCA (1 mg/mL) were prepared, as previously described, ${ }^{28}$ by adding the powder to $10 \%$ ultrapure water-soluble gel. The $\mathrm{CaCl}_{2}$ stock solution $(2 \%)$ was prepared by adding $\mathrm{CaCl}_{2}$ powder to high-performance liquid chromatography water. All preparations were mixed thoroughly at room temperature, for 4 hours, stored in the refrigerator, and used within 48 hours of preparation.

\section{Preparation of microcapsules}

Microcapsules of PB-loaded low-viscosity SA were prepared using a BÜCHI-based microencapsulating system (BÜCHI Labortechnik AG, Flawil, Switzerland). Polymer solutions containing SA and PB with or without DCA were made up to a final concentration (of PB-DCA-SA) in a ratio of $1: 3: 30$, respectively. This ratio was based on the authors' published work ${ }^{29}$ and was found to exhibit maximum consistency and best morphology. Parameters used include: a frequency range of $1,000-1,500 \mathrm{~Hz}$, air flow of $4 \mathrm{~mL} /$ minute, and a constant air pressure of 300 mbar. Microcapsules were collected from the microencapsulating system, and for each formulation, three independent batches were prepared and tested separately $(n=3)$. All microcapsules (PB-SA-loaded and PB-DCA-SA-loaded) were prepared and treated in the exact same way. Microcapsules were dried by using stability chambers (ACS Environmental and Climatic Test Chamber; Angelantoni Test Technologies Srl, Massa Martana, Italy).

\section{Characterization of loaded microcapsules: morphology, size analysis, and chemical characterization of microcapsules}

All microcapsules were freshly made, stored in the refrigerator, and used within 48 hours of preparation. The appearance and size of microcapsules were examined using light microscopy followed by scanning electron microscopy (SEM) and energy dispersive X-ray spectrometry (EDS). The particle size distribution and mean particle size diameter were calculated using the software provided.

\section{Optical microscopy}

Morphological characteristics and particle size analysis were determined with optical microscopy utilizing a YS2-H microscope (Nikon Corporation, Tokyo Japan) mounted with an FMA050 fixed calibrated microscope adaptor (ToupTek Photonics Co., Ltd., Hangzhou, People's Republic of China). Sample analysis was carried out in triplicate as previously described. ${ }^{28}$ Briefly, predetermined quantities (ten microcapsules from each formulation) of freshly prepared microcapsules were loaded onto a glass slide mounted to a calibrated scale. Optical microscopy software (ToupTek; ProSciTech, Australia) capable of particle size analysis, microcapsule 
characterization, and morphological assessments was utilized to determine basic characteristics of the microcapsules to complement the SEM studies.

\section{SEM and EDS}

The surface morphology of the microcapsules was examined using SEM (Neon 40 EsB; Carl Zeiss Meditec AG, Jena, Germany) with $0.8 \mathrm{~nm}$ calibrated resolution. The chemical characterization of the microcapsules was examined using EDS (INCA ${ }^{\circledR}$ X-Act; Oxford Instruments plc, Abingdon, UK). The samples were mounted on a glass stub with double-sided adhesive tape and coated under vacuum with platinum $(5 \mathrm{~nm})$ in an argon atmosphere prior to examination. Micrographs at different magnifications were recorded to study the morphological and surface characteristics of the microcapsules.

\section{Determination of dispersing media viscosity}

Viscosities of both preparations (PB-SA-loaded and PBDCA-SA-loaded microcapsules) were measured for freshly prepared mixtures, using $15 \mathrm{~mL}$ aliquots $(\mathrm{n}=3)$ at room temperature using a viscometer (Bohlin Visco 88; Malvern Instruments, Malvern, UK).

\section{Differential scanning calorimetric (DSC) analysis}

DSC thermograms of PB, DCA, and low-viscosity SA powders, their physical mixture, and their microencapsulated formulations were carried out in a DSC instrument (DSC 8000; PerkinElmer Inc., Waltham, MA, USA) as previously described. ${ }^{30}$ Briefly, $5 \mathrm{mg}$ samples were placed in sealed aluminum pans and heated at $20^{\circ} \mathrm{C} /$ minute under a nitrogen atmosphere (flow rate $30 \mathrm{~mL} /$ minute) in the $35^{\circ} \mathrm{C}-240^{\circ} \mathrm{C}$ range. An empty aluminum pan was used as a reference. The equipment was calibrated for baseline and temperature with zinc metal.

\section{Fourier transform infrared (FTIR) spectral studies}

FTIR spectra of pure components, their physical mixture, and the microcapsules were recorded using an attenuated total reflectance FTIR spectrometer (Spectrum $\mathrm{TWO}^{\mathrm{TM}}$; PerkinElmer), and infrared measurements were performed in transmission in the scanning range of $450-4,000 \mathrm{~cm}^{-1}$ at room temperature.

\section{Statistical analysis}

Values are expressed as mean \pm standard deviation. Size measurements were assessed using Student's $t$-test. Statistical analysis was done using a two-way analysis of variance, with Tukey's honest significant difference post hoc comparison of means used only when the associated main effect or interaction was statistically significant. The best fit model was derived using Prism ${ }^{\circledR}$ version 6.0 software (GraphPad Software, Inc., La Jolla, CA, USA). Statistical significance was set at $P<0.05$.

\section{Results and discussion Morphology, size analysis, and chemical characterization of microcapsules}

Microcapsules were obtained using a low-viscosity SA polymer, PB, and DCA at a constant ratio of 30:1:3, respectively. Using the microencapsulation system, all microcapsules were of similar size. The mean diameters ranged from 2,000-2,300 $\mu \mathrm{m}$ for all batches of both formulations, which suggest they may also be considered as macrocapsules. The mean particle size was not significantly affected by the presence of DCA.

\section{Optical microscopy}

Microcapsules obtained from optical microscopy revealed uniform consistency and spherical shaped microcapsules with similar sizes, as determined via a calibrated scale mounted onto a glass slide. Ten microcapsules were selected for particle size and morphological analysis from each formulation and repeated in triplicate. The mean diameter of PB microcapsules (average \pm standard deviation) was $2,150 \pm 150 \mu \mathrm{m}$, while that of PB-DCA-SA microcapsules was $2,350 \pm 90 \mu \mathrm{m}$. Figure 1A shows PB-SA microcapsules and Figure 1B shows PB-DCA-SA microcapsules. L1 shows the microcapsule membrane thickness, L2 shows the horizontal diameter, and L3 shows the vertical diameter. The calibrated optical microscopy size analysis revealed very similar sizes and morphological characteristics between both microencapsulated formulations, and thus the addition of DCA to PB microcapsules did not adversely affect the size, shape, or characteristics of the microcapsules.

\section{SEM}

The results from optical microscopy were further complemented by SEM data of a PB-SA microcapsule (Figure 2) and PB-DCA-SA microcapsule (Figure 3), which were randomly selected from a few batches. SEM results showed consistently uniform microcapsules with well-defined spherical shapes, and reflect the optical microscopy findings. The microcapsule size difference between different formulations was not significant, meaning the addition of DCA did not adversely affect the size, morphology, uniformity, and sphericity of 

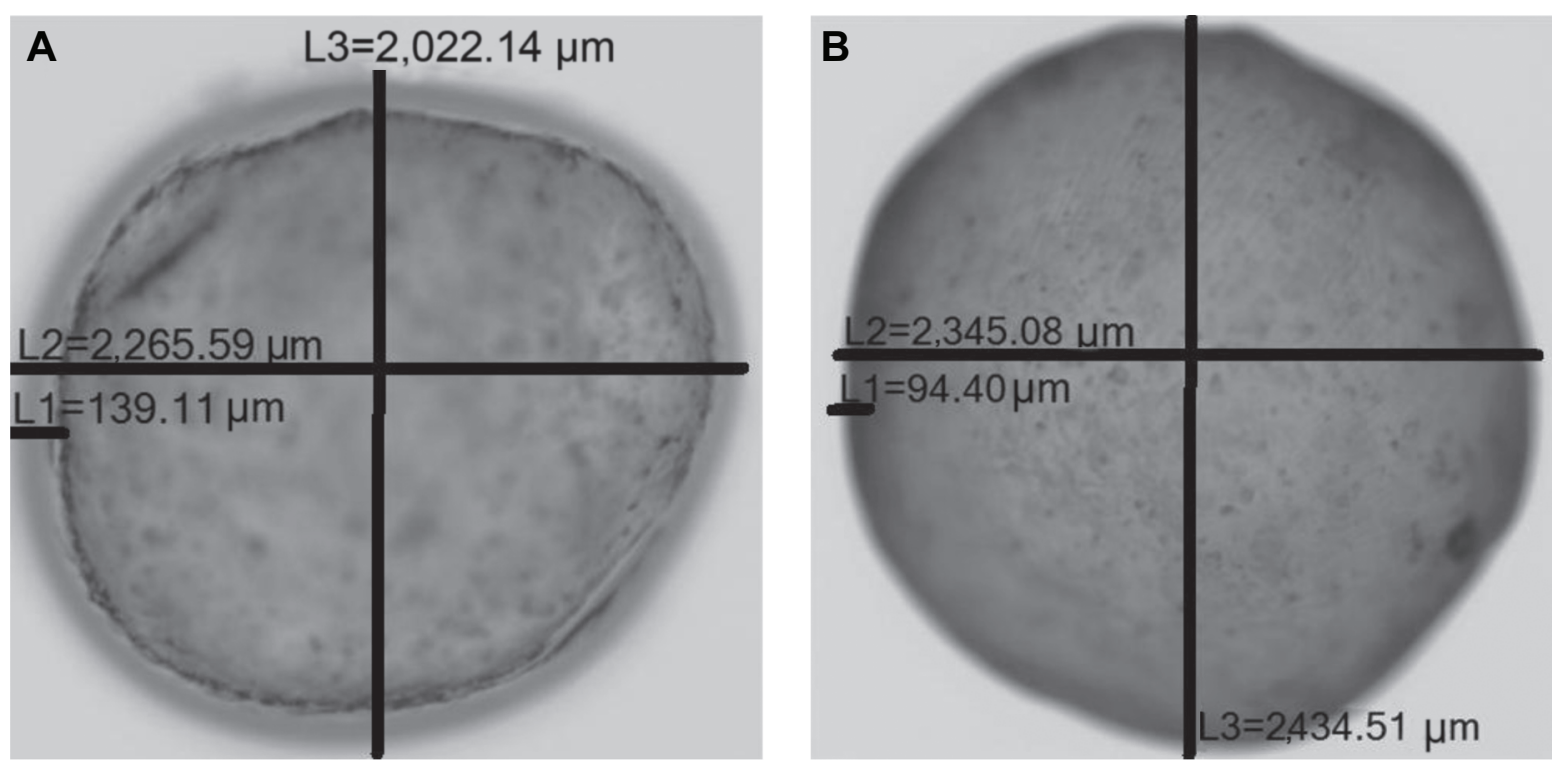

Figure I Optical microscopy of PB-SA and PB-DCA-SA microcapsules.

Notes: (A) PB-SA microcapsules. (B) PB-DCA-SA microcapsules.

Abbreviations: DCA, deoxycholic acid; LI, outer membrane thickness; L2, horizontal diameter; L3, vertical diameter; PB, probucol; SA, sodium alginate.
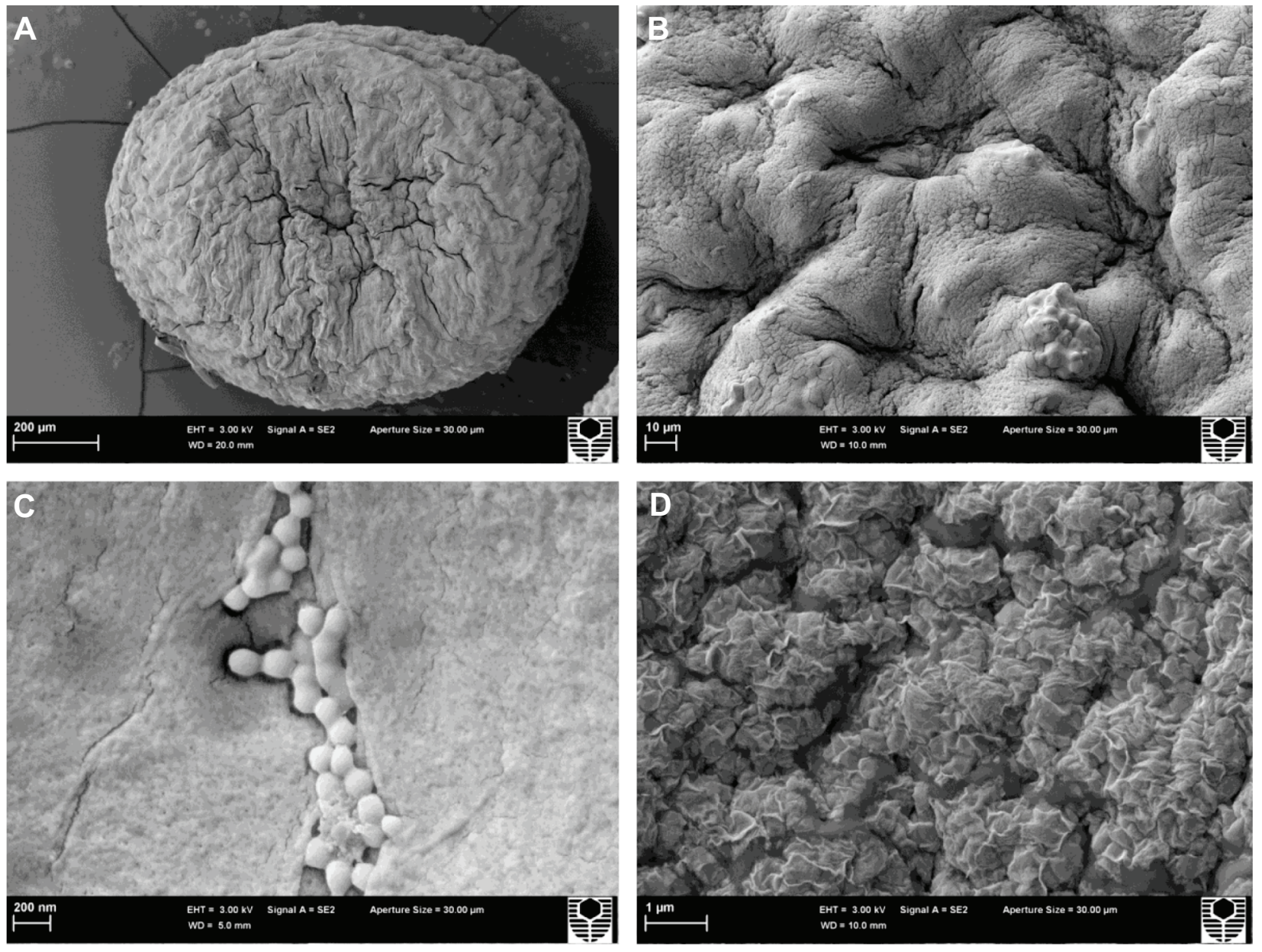

Figure 2 Scanning electron micrographs of a PB-SA microcapsule.

Notes: (A) $200 \mu \mathrm{m}$ scale. (B) Surface morphology at $10 \mu \mathrm{m}$ scale. (C) $200 \mathrm{~nm}$ scale. (D) I $\mu \mathrm{m}$ scale.

Abbreviations: PB, probucol; SA, sodium alginate. 

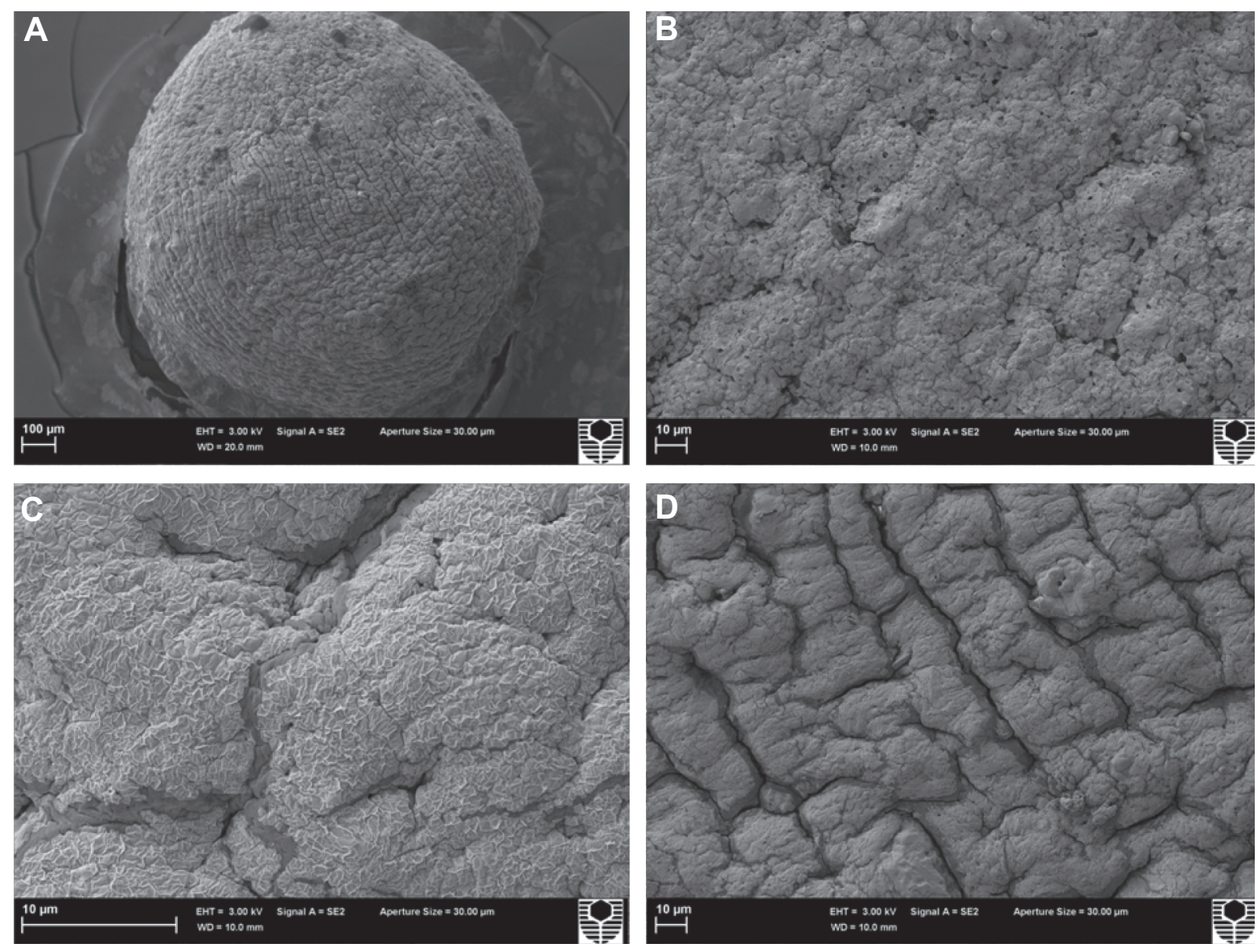

Figure 3 Scanning electron micrographs of a PB-DCA-SA microcapsule.

Notes: (A) $100 \mu \mathrm{m}$ scale. (B-D) Surface morphology from different angles at $10 \mu \mathrm{m}$ scale.

Abbreviations: DCA, deoxycholic acid; PB, probucol; SA, sodium alginate.

the microcapsules. The microcapsule surfaces were rough but consistent from one microcapsule to another. For PB-SA microcapsules, small crystals were distributed throughout the microcapsule surface (Figure 2C), either as large clumps or smaller groups. These crystals coating the microcapsule surface were believed to be $\mathrm{PB}$, but this was not observed with the PB-DCA-SA microcapsules (Figure 3). They were confirmed to be PB by EDS studies (Figures 4 and 5).

\section{EDS}

The surface composition of both PB-SA and PB-DCA-SA microcapsules were analyzed through EDS. This form of analysis allows identification of surface elemental composition, as each element from the periodic table displays unique EDS patterns. ${ }^{31}$ Surface crystal depositions and microcapsule surface composition and characteristics were also evident from this analysis. Figures 4 and 5 show an example of both PB-SA and PB-DCA-SA microcapsule surfaces with the corresponding surface sites where EDS analysis was conducted. Figures $4 \mathrm{~A}-\mathrm{B}$ and $5 \mathrm{~A}-\mathrm{B}$ show $\mathrm{PB}$ deposition on the surface of the microcapsules, while Figures 4C-D and 5C-D show general surface characteristics of the microcapsules.

EDS examination of crystal depositions on the microcapsule surfaces (Figures 4 and 5) showed high levels of sulfur atoms, evident as small crystals on the surface of PB-SA (Figures 4A and B) and, to a lesser extent, of PB-DCA-SA (Figures $5 \mathrm{~A}$ and $\mathrm{B}$ ) microcapsules. The crystals were from PB deposition as no other excipient contains sulfur. ${ }^{32-35}$ The SEM (Figures 2 and 3) and EDS (Figures 4 and 5) results suggest that $\mathrm{PB}$ preferentially coats the microcapsule surface, forming scattered clumps of drug agglomerates distributed around the microcapsule surface. Interestingly, and in line with the authors' previous studies, DCA seems to reduce the extent of PB surface deposition and the overall porosity, thus providing membrane reinforcement and improving microcapsule integrity. ${ }^{36}$

\section{Viscosity of the microencapsulated formulation}

Table 1 shows the viscosity, shear rate, shear stress, and torque for both microencapsulated formulations under various 
A

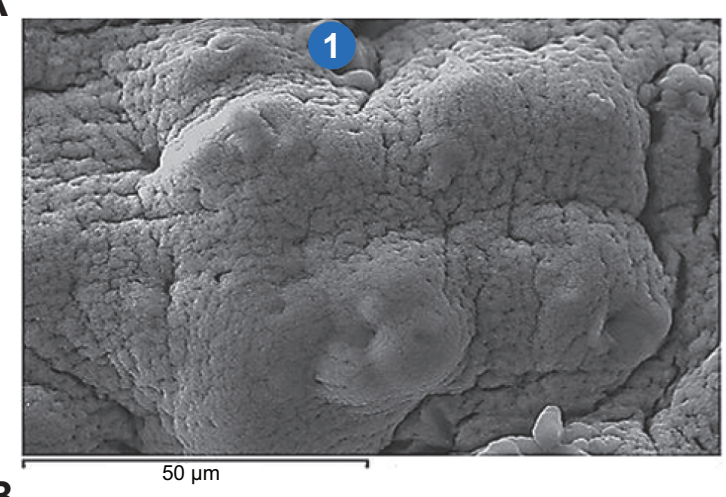

B

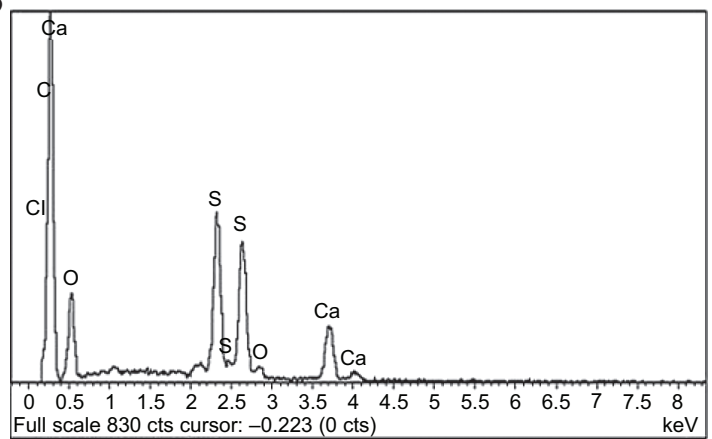

C

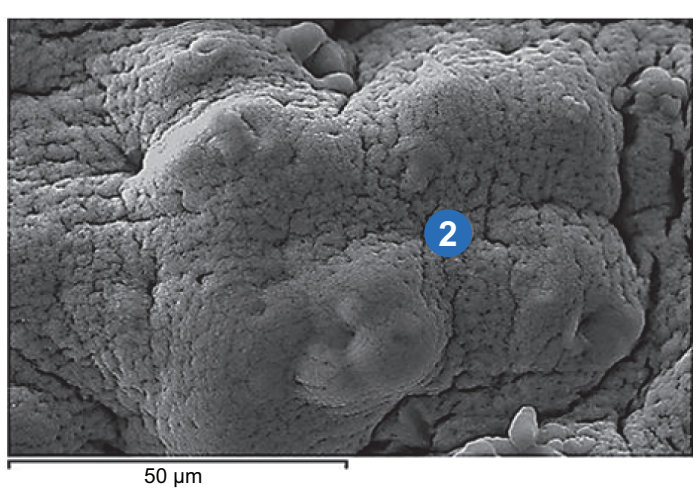

D

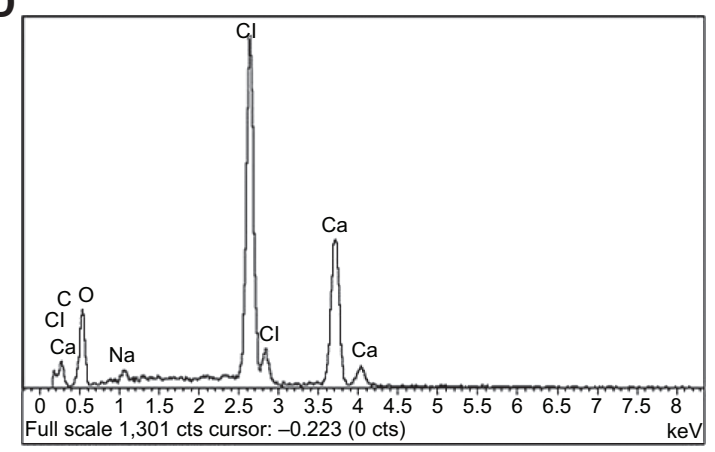

Figure 4 Energy dispersive $X$-ray spectra of PB-SA microcapsules.

Notes: (A and B) PB deposition (indicated by I) with corresponding analysis. (C and D) Surface composition (indicated by 2 ) with corresponding analysis. Abbreviations: PB, probucol; SA, sodium alginate.
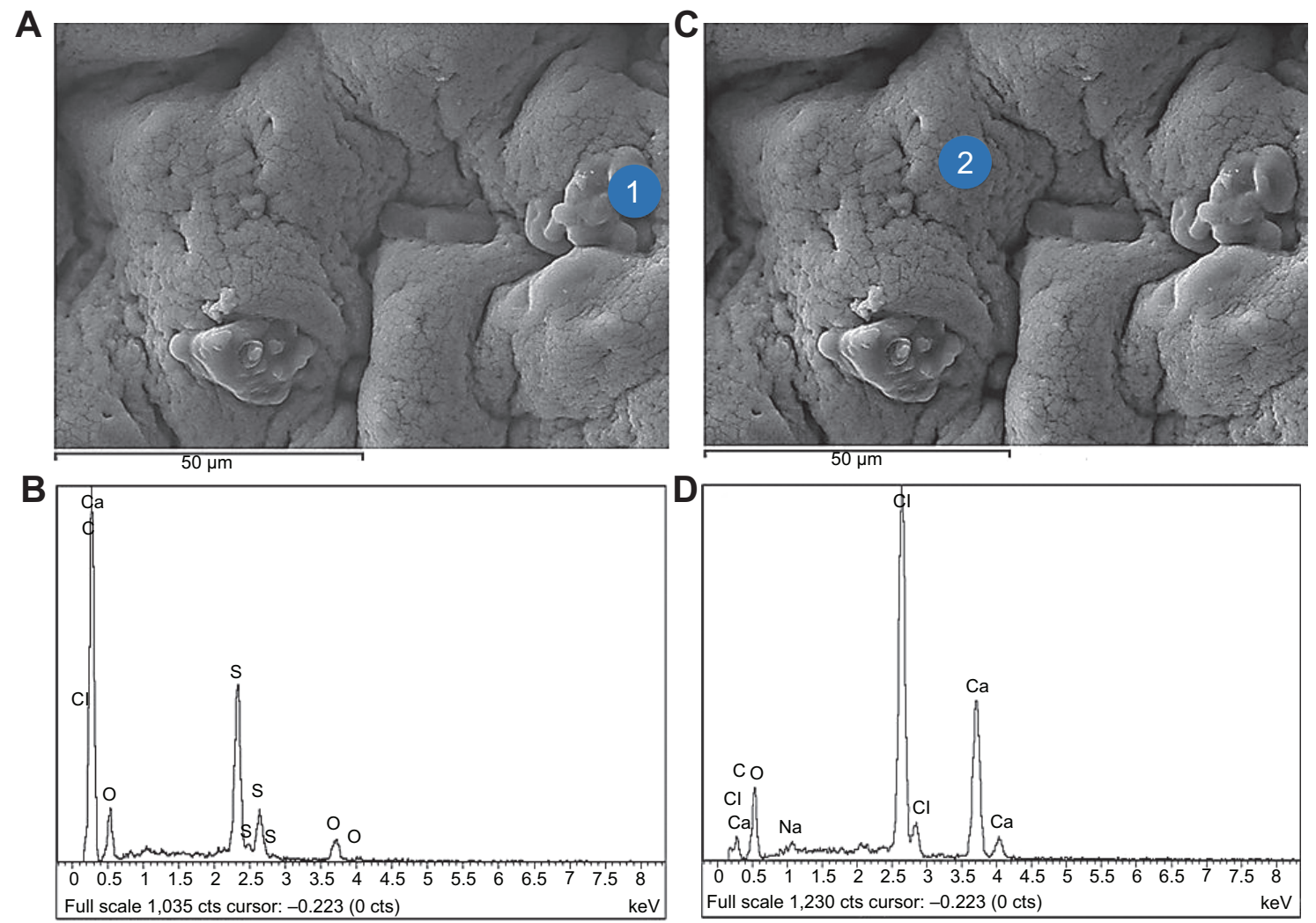

Figure 5 Energy dispersive $X$-ray spectra of PB-DCA-SA microcapsules.

Notes: (A and B) PB deposition (indicated by I) with corresponding analysis. (C and $\mathbf{D})$ Surface composition (indicated by 2 ) with corresponding analysis. Abbreviations: DCA, deoxycholic acid; PB, probucol; SA, sodium alginate. 
Table I Viscosities and related parameters of both microencapsulated formulations

\begin{tabular}{|c|c|c|c|c|c|c|}
\hline Formula code & Set speed & rpm & Viscosity (mPa.s) & Shear rate $\left(\mathrm{s}^{-1}\right)$ & Torque $(\mathrm{mNm})$ & Shear stress $(\mathrm{Pa})$ \\
\hline \multirow[t]{8}{*}{ PB-SA } & I & 20 & UD & $23.9 \pm 1$ & UD & UD \\
\hline & 2 & 35 & UD & $42.2 \pm 2$ & UD & UD \\
\hline & 3 & 61 & UD & $74.5 \pm 2$ & $0.08 \pm 0.02$ & UD \\
\hline & 4 & 107 & $25 \pm 0.2$ & $|25| \pm 2$. & $0.11 \pm 0.01$ & $3.2 \pm 0.01$ \\
\hline & 5 & 187 & $20 \pm 0.1$ & $222.2 \pm 3$ & $0.17 \pm 0.03$ & $4.5 \pm 0.01$ \\
\hline & 6 & 327 & $15 \pm 0.1$ & $385.7 \pm 4$ & $0.21 \pm 0.01$ & $5.7 \pm 0.03$ \\
\hline & 7 & 572 & $10 \pm 0.3$ & $681.8 \pm 8$ & $0.26 \pm 0.03$ & $6.9 \pm 0.02$ \\
\hline & 8 & 1,000 & $9 \pm 0.1$ & $1,194 \pm 10$ & $0.40 \pm 0.01$ & $10.9 \pm 0.01$ \\
\hline \multirow[t]{8}{*}{ PB-DCA-SA } & I & 20 & UD & $28 \pm 1$ & UD & UD \\
\hline & 2 & 35 & UD & $42.1 \pm 2$ & UD & UD \\
\hline & 3 & 61 & UD & $74.4 \pm 3$ & UD & UD \\
\hline & 4 & 107 & UD & $124.9 \pm 5$ & UD & UD \\
\hline & 5 & 187 & UD & $221.9 \pm 7$ & $0.11 \pm 0.01$ & UD \\
\hline & 6 & 327 & $12 \pm 0.2$ & $385.0 \pm 5$ & $0.16 \pm 0.03$ & $4.5 \pm 0.03$ \\
\hline & 7 & 572 & $I I \pm 0.1$ & $681 \pm 10$ & $0.27 \pm 0.02$ & $7.2 \pm 0.01$ \\
\hline & 8 & 1,000 & $10 \pm 0.2$ & $1,195 \pm 12$ & $0.43 \pm 0.01$ & $11.7 \pm 0.02$ \\
\hline
\end{tabular}

Note: $\mathrm{n}=3$. Data are described as mean $\pm S D$.

Abbreviations: DCA, deoxycholic acid; PB, probucol; SA, sodium alginate; SD, standard deviation; UD, undetected (below the instrument limit of detection).

speeds $(20,35,61,107,187,327,572$, and 1,000 rpm). The PB-SA formulation was more viscous, and both formulations behaved as non-Newtonian fluids under shear stress. ${ }^{37,38}$ Both formulations behaved as thixotropic fluids under increasing stress, as evidenced by parallel reductions in their apparent viscosity. ${ }^{39,40}$ Increasing speeds resulted in the solutions forming rapid circular motions away from the origin of the centripetal force, suggesting that both formulations also behaved in a non-Weissenberg fashion. ${ }^{41,42}$

\section{DSC}

DSC is commonly used for the thermal characterization of various materials..$^{43,44}$ In PB microencapsulation, DSC measures how physical properties of $\mathrm{PB}$ molecules change, along with temperature, against time. ${ }^{45}$ This occurs through determining the temperature and heat flow $\left(35^{\circ} \mathrm{C}-240^{\circ} \mathrm{C}\right)$ associated with PB transitions as a function of time..$^{45}$ DSC spectra were analyzed for PB powder (Figure 6A), DCA powder (Figure 6B), SA powder (Figure 6C), PB-DCA-SA physical powder mixture (Figure 6D), PB-SA microcapsules (Figure 6E), and PB-DCA microcapsules (Figure 6F).

PB powder analysis (Figure 6A) showed a large peak at $128^{\circ} \mathrm{C}$, which corresponds to the melting point of PB. ${ }^{45,46}$ DCA powder analysis (Figure 6B) showed a small peak at $178^{\circ} \mathrm{C}$, which corresponds to the melting point of DCA. ${ }^{36}$ SA powder (Figure 6C) showed a large peak at $200^{\circ} \mathrm{C}$, which corresponds to the melting point of SA. ${ }^{47}$ PB-DCA-SA physical powder mixture (Figure 6D) showed only two distinct peaks, one peak at $130^{\circ} \mathrm{C}$, which corresponds to $\mathrm{PB}$, and one at $200^{\circ} \mathrm{C}$, which corresponds to SA. The slight shift to the right in both peaks suggests an increase in the melting point of the combined mixture, which reflects findings from the authors' previous work. ${ }^{48}$ PB-DCA-SA powder analysis only showed two peaks, PB and SA, while the peak that corresponds to DCA was missing, possibly due to a shift in the thermal capacity within the $35^{\circ} \mathrm{C}-240^{\circ} \mathrm{C}$ range or due to an overlap between DCA and SA peaks. ${ }^{45}$ The PB-SA microcapsule (Figure 6E) showed two peaks - a small peak at $128^{\circ} \mathrm{C}$, which corresponds to the melting point of $\mathrm{PB}$, and a large peak at $202^{\circ} \mathrm{C}$, which corresponds to the melting point of SA - with a slight shift to the right possibly due to ionic interaction between $\mathrm{PB}$ and SA post-microencapsulation. The PB-DCA-SA microcapsule (Figure 6F) showed two peaks, similar to the PB-DCA-SA powder mixture (Figure 6D). Overall, DSC analysis showed a transparent and interference-free integration of two prominent peaks - one corresponding to $\mathrm{PB}$ and the other to SA, with the possibility of overlap between DCA and SA. There was a noticeable slight shift pre- and post-microencapsulation, which could represent potential chemical interactions between SA and DCA in the microcapsule matrix, alterations in the crystallinity, polymorphism, and plasticization of SA, or a possible combination of factors leading to an endothermic shift. ${ }^{49}$ Most importantly, PB did not seem to significantly participate in a crosslinking reaction, and retained its chemical integrity during the microencapsulation process, which is also supported by the FTIR results (Figure 7). ${ }^{45,46}$ 

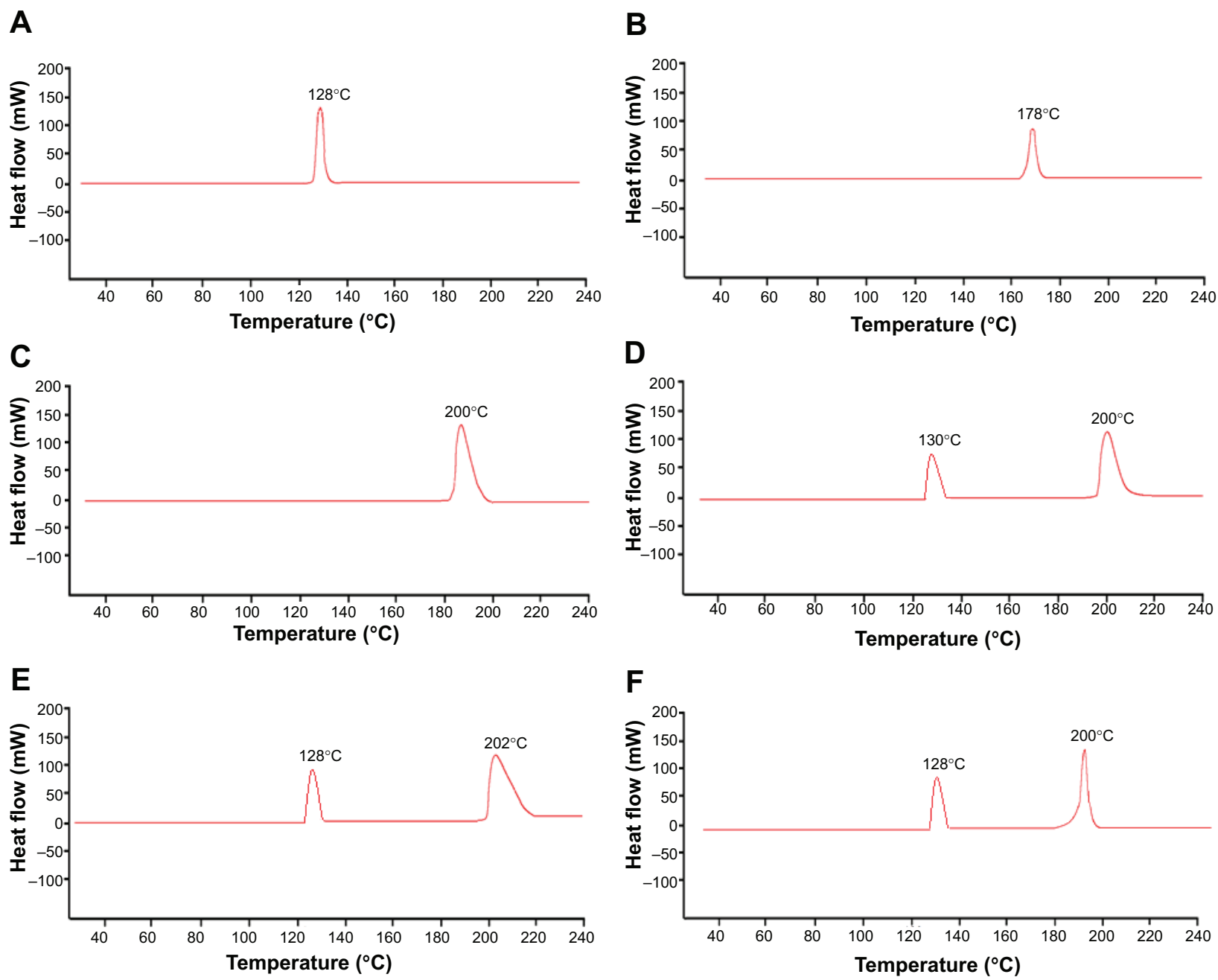

Figure 6 Differential scanning calorimetric thermograms of the individual powders, mixed powder containing all the ingredients, and microcapsules. Notes: (A) PB powder. (B) DCA powder. (C) SA powder. (D) PB-DCA-SA powder. (E) PB-SA microcapsules. (F) PB-DCA-SA microcapsules. Abbreviations: DCA, deoxycholic acid; PB, probucol; SA, sodium alginate.

\section{FTIR spectral studies}

The FTIR method is widely used to stimulate vibrational levels of known chemical groups in a molecule, and was used to confirm the chemical compatibility of $\mathrm{PB}$ with the SA polymer and DCA in the microencapsulation formulation. ${ }^{45}$ In line with the DSC analysis (Figure 5), FTIR spectra were analyzed for PB powder (Figure 7A), DCA powder (Figure 7B), SA powder (Figure 7C), PB-DCA-SA powder (Figure 7D), PB-SA microcapsules (Figure 7E), and PB-DCA-SA microcapsules (Figure 7F). FTIR spectral analysis of individual powders, mixed powders containing all the ingredients, and final microcapsules attained was necessary to ensure the chemical compatibility of $\mathrm{PB}$ pre- and post-microencapsulation.

FTIR PB powder analysis (Figure 7A) showed characteristic peaks at 2,959, 1,422, and $1,310 \mathrm{~cm}^{-1}$. DCA and SA individual powder analysis (Figures $7 \mathrm{~B}$ and $\mathrm{C}$ ) showed similar characteristics to the authors' published work. ${ }^{27}$
The PB-DCA-SA physical powder mixture (Figure 7D) showed peaks that correspond to $\mathrm{PB}, \mathrm{DCA}$, and SA with no interference, dilution, or alterations. This confirms compatibility of all the ingredients in the powder form pre-microencapsulation. PB-SA microcapsule analysis (Figure 7E) showed five distinct and interference-free peaks, which correspond to PB and SA analysis, at 3,350, 1,422, 1,309, 1,602, and 1,025 $\mathrm{cm}^{-1}$. Similar peaks were noticed after DCA addition, which is in line with the DSC findings (Figure 6), suggesting an interaction between DCA and SA. PB-DCA-SA microcapsule analysis (Figure 7F) showed three PB peaks (at 3,350, 1,426, and 1,309 $\mathrm{cm}^{-1}$ ) and two SA peaks (at 1,601 and 1,025 $\mathrm{cm}^{-1}$ ), which is in line with the DSC analysis (Figure 6F).

Overall, FTIR analysis showed compatibility of the formulation pre- and post-microencapsulation. The absence of DCA peaks is in line with the DSC analysis (Figure 6) and the authors' previously published work,${ }^{28}$ and suggests an 
A

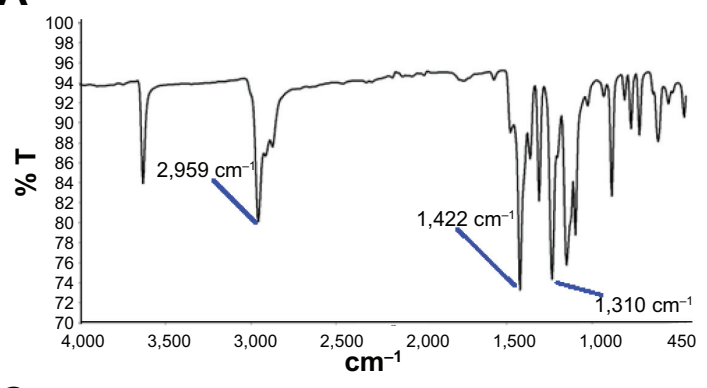

C ${ }_{100}$

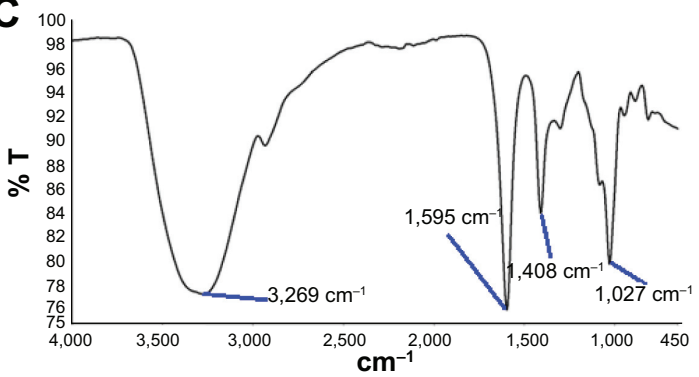

$E_{10}$

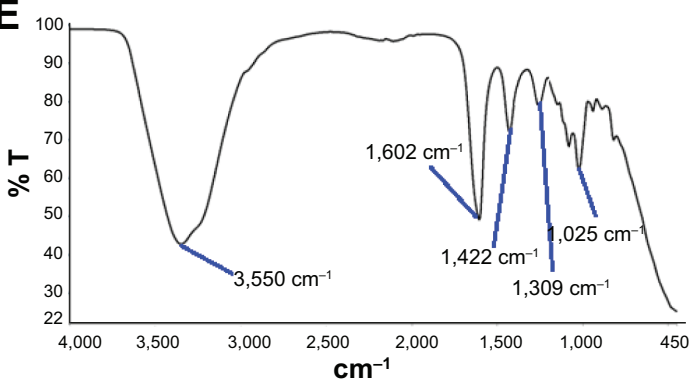

\section{B}
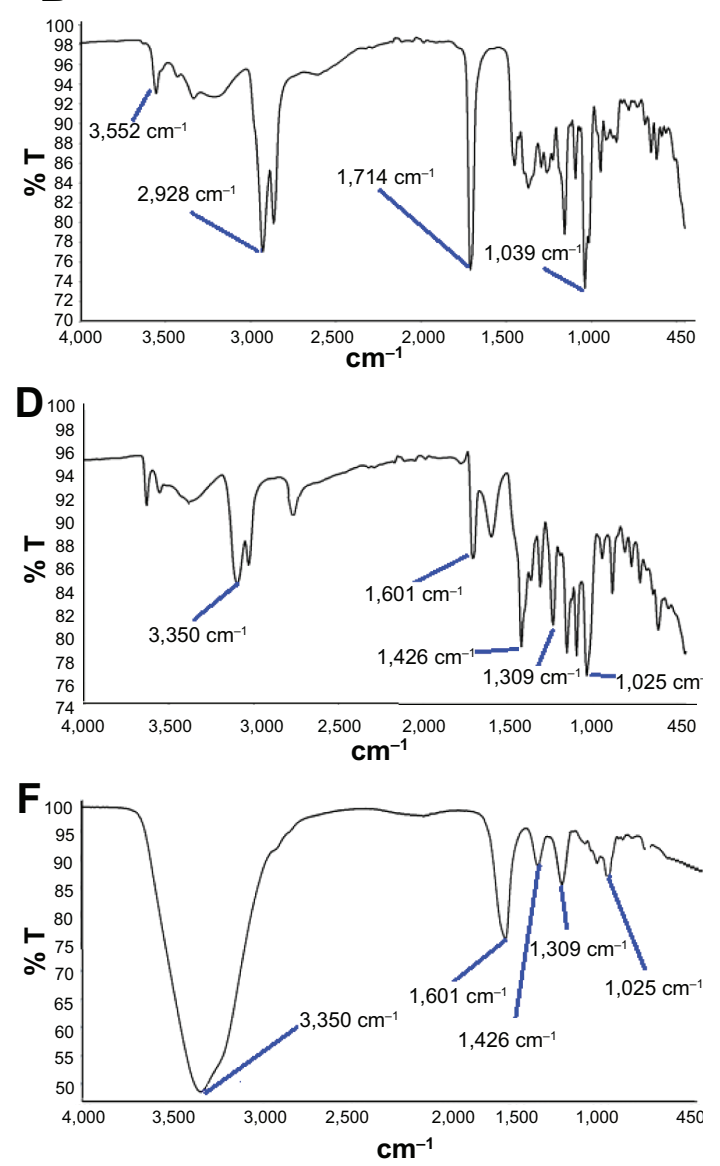

Figure 7 Fourier transform infrared spectra of the individual powders, mixed powder containing all the ingredients, and microcapsules.

Notes: (A) PB powder. (B) DCA powder. (C) SA powder. (D) PB-DCA-SA powder. (E) PB-SA microcapsules. (F) PB-DCA-SA microcapsules.

Abbreviations: DCA, deoxycholic acid; PB, probucol; T, transmitted light; SA, sodium alginate.

interaction between DCA and the polymer SA. However, this interaction did not interfere with $\mathrm{PB}$ peaks as shown by the chemical (FTIR) and thermal (DSC) analyses. This suggests PB stability pre- and post-microencapsulation, as its chemical composition and structural integrity were maintained when microencapsulated with DCA.

This is a comprehensive study with in-depth in vitro analysis of novel bile acid-PB microcapsules with good potential in the treatment of T2D. A major limitation, and thus future work, is in vivo analysis carried out by administering these microcapsules to an animal model of T2D and elucidating efficacy and safety profiles.

\section{Conclusion}

PB-DCA-SA microcapsules showed good morphology and stability and may be suitable for optimized oral delivery of $\mathrm{PB}$ in T2D. A future study may investigate the release kinetics and $\mathrm{pH}$-targeted delivery of the microcapsules at various $\mathrm{pH}$ and temperature values.

\section{Acknowledgments}

The authors acknowledge the Curtin Health Innovation Research Institute at Curtin University, and the Curtinseeding grant for the support, and also acknowledge the use of equipment and scientific and technical assistance of the Curtin University Electron Microscope Facility, which has been partially funded by the University, State, and Commonwealth Governments.

\section{Disclosure}

The authors report no conflicts of interest in this work.

\section{References}

1. Barnett R. Historical keyword: diabetes. Lancet. 2010;375(9710):191.

2. Torpy JM, Lynm C, Glass RM. JAMA patient page: diabetes. JAMA. 2009;301(15):1620.

3. Barbeau WE, Bassaganya-Riera J, Hontecillas R. Putting the pieces of the puzzle together - a series of hypotheses on the etiology and pathogenesis of type 1 diabetes. Med Hypotheses. 2007;68(3):607-619.

4. Moore PA, Zgibor JC, Dasanayake AP. Diabetes: a growing epidemic of all ages. J Am Dent Assoc. 2003;134 Spec No:11S-15S. 
5. Larsen N, Vogensen FK, van den Berg FW, et al. Gut microbiota in human adults with type 2 diabetes differs from non-diabetic adults. PLoS One. 2010;5(2):e9085.

6. Johansen JS, Harris AK, Rychly DJ, Ergul A. Oxidative stress and the use of antioxidants in diabetes: linking basic science to clinical practice. Cardiovasc Diabetol. 2005;4(1):5.

7. Cani PD, Neyrinck AM, Fava F, et al. Selective increases of bifidobacteria in gut microflora improve high-fat-diet-induced diabetes in mice through a mechanism associated with endotoxaemia. Diabetologia. 2007;50(11):2374-2383.

8. Heel RC, Brogden RN, Speight TM, Avery GS. Probucol: a review of its pharmacological properties and therapeutic use in patients with hypercholesterolaemia. Drugs. 1978;15(6):409-428.

9. Zimetbaum P, Eder H, Frishman W. Probucol: pharmacology and clinical application. J Clin Pharmacol. 1990;30(1):3-9.

10. Yamashita S, Matsuzawa Y. Where are we with probucol: a new life for an old drug? Atherosclerosis. 2009;207(1):16-23.

11. Crim WS, Wu R, Carter JD, et al. AGI-1067, a novel antioxidant and anti-inflammatory agent, enhances insulin release and protects mouse islets. Mol Cell Endocrinol. 2010;323(2):246-255.

12. Karunakaran U, Park KG. A systematic review of oxidative stress and safety of antioxidants in diabetes: focus on islets and their defense. Diabetes Metab J. 2013;37(2):106-112.

13. Takatori A, Ohta E, Inenaga T, et al. Protective effects of probucol treatment on pancreatic beta-cell function of SZ-induced diabetic APA hamsters. Exp Anim. 2003;52(4):317-327.

14. Gorogawa S, Kajimoto Y, Umayahara Y, et al. Probucol preserves pancreatic beta-cell function through reduction of oxidative stress in type 2 diabetes. Diabetes Res Clin Pract. 2002;57(1):1-10.

15. Russell JC, Graham SE, Amy RM, Dolphin PJ. Cardioprotective effect of probucol in the atherosclerosis-prone JCR:LA-cp rat. Eur J Pharmacol. 1998;350(2-3):203-210.

16. Palin KJ, Wilson CG. The effect of different oils on the absorption of probucol in the rat. J Pharm Pharmacol. 1984;36(9):641-643.

17. Tanaka Y, Inkyo M, Yumoto R, Nagai J, Takano M, Nagata S. Nanoparticulation of probucol, a poorly water-soluble drug, using a novel wet-milling process to improve in vitro dissolution and in vivo oral absorption. Drug Dev Ind Pharm. 2012;38(8):1015-1023.

18. Heeg JF, Hiser MF, Satonin DK, Rose JQ. Pharmacokinetics of probucol in male rats. J Pharm Sci. 1984;73(12):1758-1763.

19. Lalic-Popovic M, Vasovic V, Milijasevic B, Golocorbin-Kon S, Al-Salami H, Mikov M. Deoxycholic acid as a modifier of the permeation of gliclazide through the blood-brain barrier of a rat. J Diabetes Res. 2013;2013:598603

20. Negrulj R, Mooranian A, Al-Salami H. Potentials and limitations of bile acids in type 2 diabetes mellitus: applications of microencapsulation as a novel oral delivery system. Journal of Endocrinology and Diabetes Mellitus. 2013;1(2):49-59.

21. Whelehan M, Marison IW. Microencapsulation using vibrating technology. J Microencapsul. 2011;28(8):669-688.

22. Al-Salami H, Butt G, Fawcett JP, Tucker IG, Golocorbin-Kon S, Mikov M. Probiotic treatment reduces blood glucose and increases systemic absorption of gliclazide in diabetic rats. Eur J Drug Metab Pharmacokinet. 2008;32(2):101-106.

23. Al-Salami H, Butt G, Tucker I, et al. Gliclazide reduces MKC intestinal transport in healthy but not diabetic rats. Eur J Drug Metab Pharmacokinet. 2009;34(1):43-50.

24. Al-Salami H, Butt G, Tucker I, Mikov M. Influence of the semisynthetic bile acid MKC on the ileal permeation of gliclazide in vitro in healthy and diabetic rats treated with probiotics. Methods Find Exp Clin Pharmacol. 2008;30(2):107-113.

25. Al-Salami H, Butt G, Tucker IG, Mikov M. The influence of probiotic pretreatment on the ilealpermeation of gliclazide in healthy and diabetic rats. Arch Drug lnf. 2008;1(1):35-41.

26. Al-Salami H, Butt G, Tucker I, Skrbic R, Golocorbin-Kon S, Mikov M. Probiotic pre-treatment reduces gliclazide permeation (ex vivo) in healthy rats but increases it in diabetic rats to the level seen in untreated healthy rats. Arch Drug Inf. 2008;1(1):35-41.
27. Mooranian A, Negrulj R, Mathavan S, et al. A complex microencapsulated system: a platform for optimized oral delivery of antidiabetic drug-bile acid formulations. Pharm Dev Technol. Epub 2014 May 5.

28. Mooranian A, Negrulj R, Chen-Tan N, et al. Microencapsulation as a novel delivery method for the potential antidiabetic drug, probucol. Drug Des Devel Ther. In press 2014.

29. Mooranian A, Negrulj R, Mathavan S, et al. Stability and release kinetics of an advanced gliclazide-cholic acid formulation: the use of artificial-cell microencapsulation in slow release targeted oral delivery of antidiabetics. J Pharm Innov. 2014;9:150-157.

30. Mooranian A, Negrulja R, Chen-Tan N, et al. Novel artificial cell microencapsulation of a complex gliclazide-deoxycholic bile acid formulation: a characterization study. Drug Des Devel Ther. 2014;8: $1003-1112$.

31. Tam SK, Dusseault J, Polizu S, Menard M, Halle JP, Yahia L. Physicochemical model of alginate-poly-L-lysine microcapsules defined at the micrometric/nanometric scale using ATR-FTIR, XPS, and ToF-SIMS. Biomaterials. 2005;26(34):6950-6961.

32. Davignon J. Probucol. In: Schettler G, Habenicht AJR, editors. Principles and Treatment of Lipoprotein Disorders. Berlin: Springer; 1994:429-469.

33. George M, Abraham TE. Polyionic hydrocolloids for the intestinal delivery of protein drugs: alginate and chitosan - a review. $J$ Control Release. 2006;114(1):1-14.

34. Kandrac J, Kevresan S, Gu JK, Mikov M, Fawcett JP, Kuhajda K. Isolation and determination of bile acids. Eur J Drug Metab Pharmacokinet. 2006;31(3):157-177.

35. Kuhajda K, Kandrac J, Kevresan S, Mikov M, Fawcett JP. Structure and origin of bile acids: an overview. Eur J Drug Metab Pharmacokinet. 2006;31(3):135-143.

36. Takka S, Cali AG. Bile salt-reinforced alginate-chitosan beads. Pharm Dev Technol. 2012;17(1):23-29.

37. Yang Y, Campanella OH, Hamaker BR, Zhang G, Gu Z. Rheological investigation of alginate chain interactions induced by concentrating calcium cations. Food Hydrocoll. 2013;30(1):26-32.

38. Bonino CA, Samorezov JE, Jeon O, Alsberg E, Khan SA. Real-time in situ rheology of alginate hydrogel photocrosslinking. Soft Matter. 2011; 7(24):11510-11517.

39. de Celis Alonso B, Rayment P, Ciampi E, et al. NMR relaxometry and rheology of ionic and acid alginate gels. Carbohydr Polym. 2010;82(3): 663-669.

40. Draget KI, Taylor C. Chemical, physical, and biological properties of alginates and their biomedical implications. Food Hydrocoll. 2011; 25(2):251-256.

41. Pamies R, Rodriguez Schmidt R, Lopez Martinez MDC, Garcia de la Torre J. The influence of mono and divalent cations on dilute and non-dilute aqueous solutions of sodium alginates. Carbohydr Polym. 2010;80(1):248-253.

42. Legrand J, Dumont E, Comiti J, Fayolle F. Diffusion coefficients of ferricyanide ions in polymeric solutions - comparison of different experimental methods. Electrochim Acta. 2000;45(11): 1791-1803.

43. Sarmento B, Ferreira D, Veiga F, Ribeiro A. Characterization of insulin-loaded alginate nanoparticles produced by ionotropic pregelation through DSC and FTIR studies. Carbohydr Polym. 2006; 66(1):1-7.

44. Gill P, Moghadam TT, Ranjbar B. Differential scanning calorimetry techniques: applications in biology and nanoscience. $J$ Biomol Tech. 2010;21(4):167-193

45. Ajun W, Yan S, Li G, Huili L. Preparation of aspirin and probucol in combination loaded chitosan nanoparticles and in vitro release study. Carbohydr Polym. 2009;75(4):566-574.

46. Thybo P, Pedersen BL, Hovgaard L, Holm R, Mullertz A. Characterization and physical stability of spray dried solid dispersions of probucol and PVP-K30. Pharm Dev Technol. 2008;13(5):375-386.

47. Soares JP, Santos JE, Chierice GO, Cavalheiro ETG. Thermal behavior of alginic acid and its sodium salt. Ecletica Quimica. 2004;29(2): $57-64$. 
48. Mooranian A, Negruli R, Mathavan S, et al. Stability and release kinetics of an advanced gliclazide-cholic acid formulation: the use of artificial-cell microencapsulation in slow release targeted oral delivery of antidiabetics. J Pharm Innov. 2014;9:150-157.
49. Kulkarni AR, Soppimath KS, Aminabhavi TM, Rudzinski WE. In-vitro release kinetics of cefadroxil-loaded sodium alginate interpenetrating network beads. Eur J Pharm Biopharm. 2001;51(2):127-133.

\section{Publish your work in this journal}

Drug Design, Development and Therapy is an international, peerreviewed open-access journal that spans the spectrum of drug design and development through to clinical applications. Clinical outcomes, patient safety, and programs for the development and effective, safe, and sustained use of medicines are a feature of the journal, which has also been accepted for indexing on PubMed Central. The manuscript management system is completely online and includes a very quick and fair peer-review system, which is all easy to use. Visit http://www.dovepress.com/testimonials.php to read real quotes from published authors.

Submit your manuscript here: http://www.dovepress.com/drug-design-development-and-therapy-journal 